\title{
Functional Independence in the Community Dwelling Older People: a Scoping Review
}

\author{
E. A. L. M. Molenaar ${ }^{1,2} \cdot$ J. A. Barten ${ }^{1} \cdot$ S. te Velde $^{1} \cdot$ L. van der Schoot $^{3}$. \\ N. Bleijenberg ${ }^{4,5} \cdot$ N. J. de Wit ${ }^{4,5} \cdot$ C. Veenhof ${ }^{1,2,5}$
}

Received: 19 November 2019 / Accepted: 5 November 2020/Published online: 24 November 2020

(C) The Author(s) 2020

\begin{abstract}
Ageing potentially poses a threat to independent functioning of older adults. Although clinicians commonly focus on physical factors limiting Functional Independence (FI), it is likely that personal and environmental interactions also seem important to maintain FI. Herewith, FI exceeds several professional borders and calls for a uniform, multidisciplinary interdisciplinary supported definition of FI. This study aims to provide such a definition of FI in community dwelling older people. A scoping review was performed. Pubmed/Medline, Psychinfo and CINAHL were searched for studies describing aspects of FI. A literature-based definition of FI was discussed by experts $(n=$ 7), resulting in a formulated final definition of FI and insight into contributing factors to FI. A multidisciplinairy focusgroup a stakeholder consultation $(n=15)$ ensured clinical relevance for daily practice. Data from the focusgroup stakeholder consultation were analyzed by using Atlas.ti (version 8). Based on the literature search, 25 studies were included. FI was finally defined as "Functioning physically safely and independent from another person, within one's own context". The contributing factors of FI comprised physical capacity combined with coping, empowerment and health literacy. Moreover, the level of FI is influenced by someone's own context. This study confirms the relevance of the physical aspect of FI, but additionally stresses the importance of psychological factors. In addition, this study shows that one's context may affect the level of FI as well. This underlines the importance of a holistic view and calls for multidisciplinary interdisciplinary collaboration in community-dwelling older people.
\end{abstract}

Keywords Functional independence · Older adults · Independence $\cdot$ Interprofessional relations $\cdot$ Patient centered care $\cdot$ Prevention $\cdot$ Holistic care

E. A. L. M. Molenaar

esther.molenaar@hu.nl

Extended author information available on the last page of the article 


\section{Introduction}

Ageing and the accompanying long-term diseases in the older population potentially pose a threat to self-sufficient functioning of older adults in their own environment. Following a downward spiral, the progressive deterioration in physical capacity associated with ageing may lead to physical frailty and for instance a higher risk on falling. Subsequently, this physical decline causes limitations both in functional performance and (instrumental) daily life activities. In the end, someone's 'Functional Independence' (FI), is at stake (Ardali et al. 2017; Clark and Manini 2010; Freedman et al. 2002). FI has been described as the ability of an individual to perform activities of daily living (Curzel et al. 2013). Several studies have shown that older adults with limitations in their FI make disproportionate use of hospital services (Mortenson et al. 2018). Early insight into factors limiting individuals' FI may contribute to better preservation of daily life activities and to use less of health care services. It may also facilitate older people in living independently, in their own environment for as long as possible (Angus et al. 2005). Moreover, monitoring FI is in line with current health care policy promoting self-sufficiency to maintain quality of life in older people. Finally, focusing on patient's FI may include a shift from the relatively expensive secondary health care towards less expensive primary care (Bodenheimer 2005; Coulter (1995); Freedman et al. 2002; Huber et al. 2011).

At this moment, different instruments are already available for clinical healthcare professionals to asses factors limiting FI and to evaluate someone's FI in daily life activities (Edwards et al. 2017). Examples are the Functional Independence Measure, the Barthel index and the Katz Index of independence in activities of daily living (Glenny and Stolee 2009; Mahoney and Barthel 1965; Wallace et al. 2007). Those instruments are commonly used in clinical practice by several professionals who are involved in the issue of FI. Physiotherapists, occupational therapists, nurses and physicians use those instruments to specifically assess the physical aspect of FI. However, from an integrated health care perspective, it is likely that FI exceeds the physical domain. According to such an integrated health care model as the International Classification of Functioning, Disability and Health (ICF) it is likely that in addition to physical capabilities, personal and environmental interactions are equally important in maintaining FI of older people (Ustun et al. 2003; de Carvalho et al. 2018). At this moment, a clear definition of such an integrated concept of FI is lacking (Collins 2017). To optimize interprofessional collaboration to prevent a decline in FI, a uniform, integral definition is required (Sangaleti et al. 2017). We report the results of a scoping review and present an interprofessionally supported definition of FI and an ICF-structured overview of factors influencing FI in community dwelling older people.

\section{Methods}

A scoping review was conducted, combining an explorative literature search with expert consultations, to develop a broad, interdisciplinary definition of FI. The fivestage framework for producing a scoping literature review, proposed by Arksey and 
O’Mally, was used as guidance (Arksey and O'Malley 2005; Colquhoun et al. 2014) The subsequent steps will be described below.

\section{1) Identifying the research question}

The research questions were twofold: (1) to determine a clinically applicable, interprofessionally supported definition of FI in the community dwelling older people. (2) to determine which factors help to identify FI and the relationship between these factors. The overall aim was to create a comprehensive overview of FI for clinical practice, fitting to the integrative ICF framework.

\section{2) Identifying relevant studies}

To create a literature based definition of FI., a medical information specialist (LS) performed an extensive search in medical electronic databases MEDLINE, CINAHL and PsycINFO. The extended search strategy was presented in Table 1. Databases were searched from the date of database start until May 2017, an update of the search in MEDLINE was conducted in July 2019. Clinicians seem to commonly focus on physical factors limiting independence. Hence to get insight into the relationship and contributing factors the term "physical" needed to be combined with "independence" or a related term. In addition, the search was carried out for a vulnerable population. 'Vulnerable' was attributed by people with several chronic diseases who are at risk for diminished FI. The search was limited to publications written in English, Dutch or German.

\section{3) Selecting the studies}

Articles were considered eligible for inclusion when both an independence component and a physical component were described. Moreover, potentially eligible studies included a vulnerable population for losing FI as in suffering from a long-term disease, frailty or older of age. The operationalization of the independence component, physical component and vulnerability was presented in Table 1. Considering the explorative aspect of the review, all research papers were considered for inclusion. In general no exclusion criteria were applied.

Prior to the selection process, duplicates were removed. Selection of eligible studies was performed following a drop-out procedure, starting with scanning of the study titles only, (Mateen et al. 2013) followed by screening of the abstracts and in the end of the full-text articles against the selection criteria. The selection procedure was performed independently by two authors (EM and JAB).

After each selection stage, differences in inclusion between the authors were resolved in a consensus meeting. Articles not available as full text were excluded, although corresponding authors were contacted when full text was not available online.

\section{4) Charting the data}

To provide an overview of the included studies, study characteristics were extracted by identifying a study's authors, publishing date, study type, research design and the 

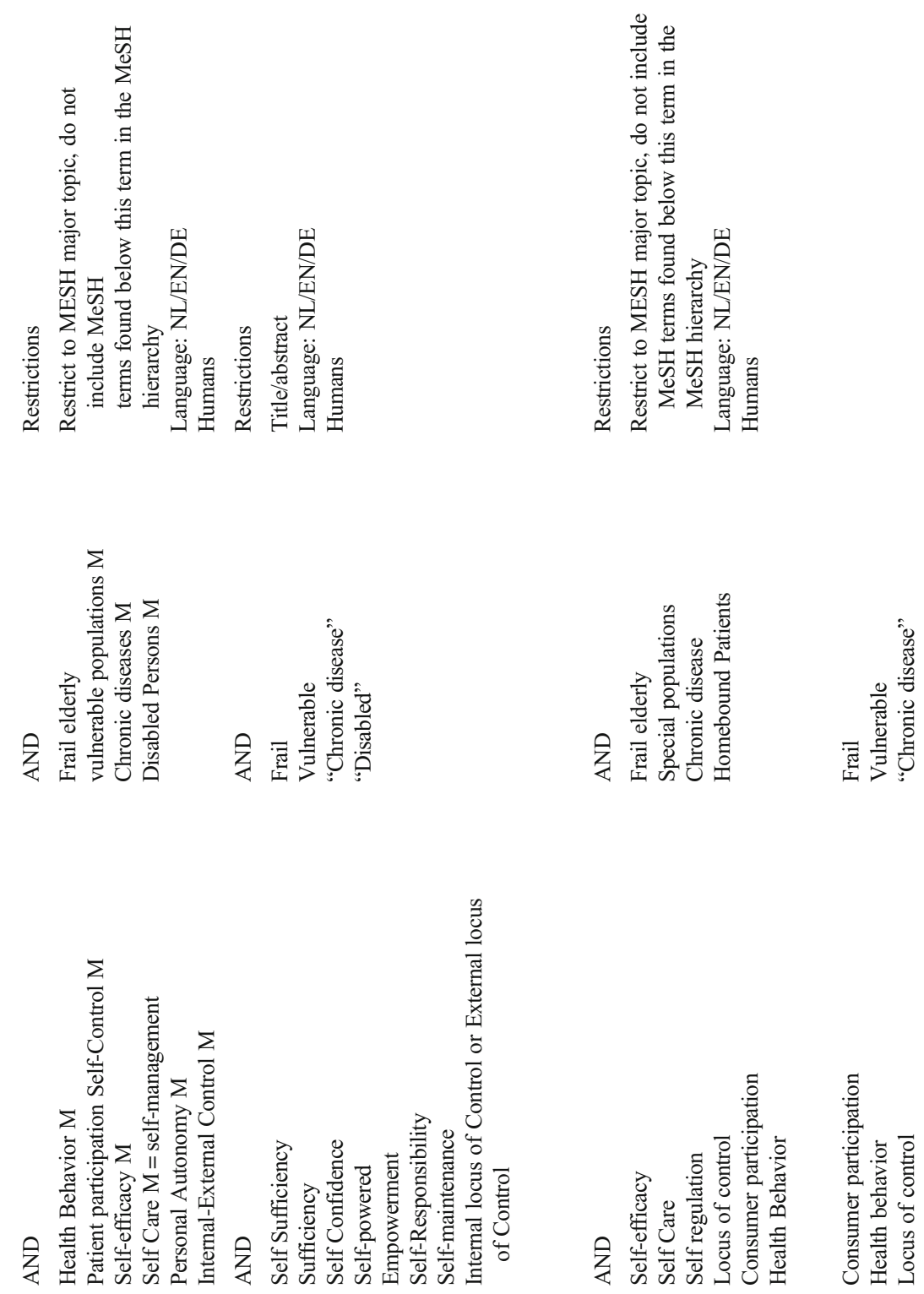


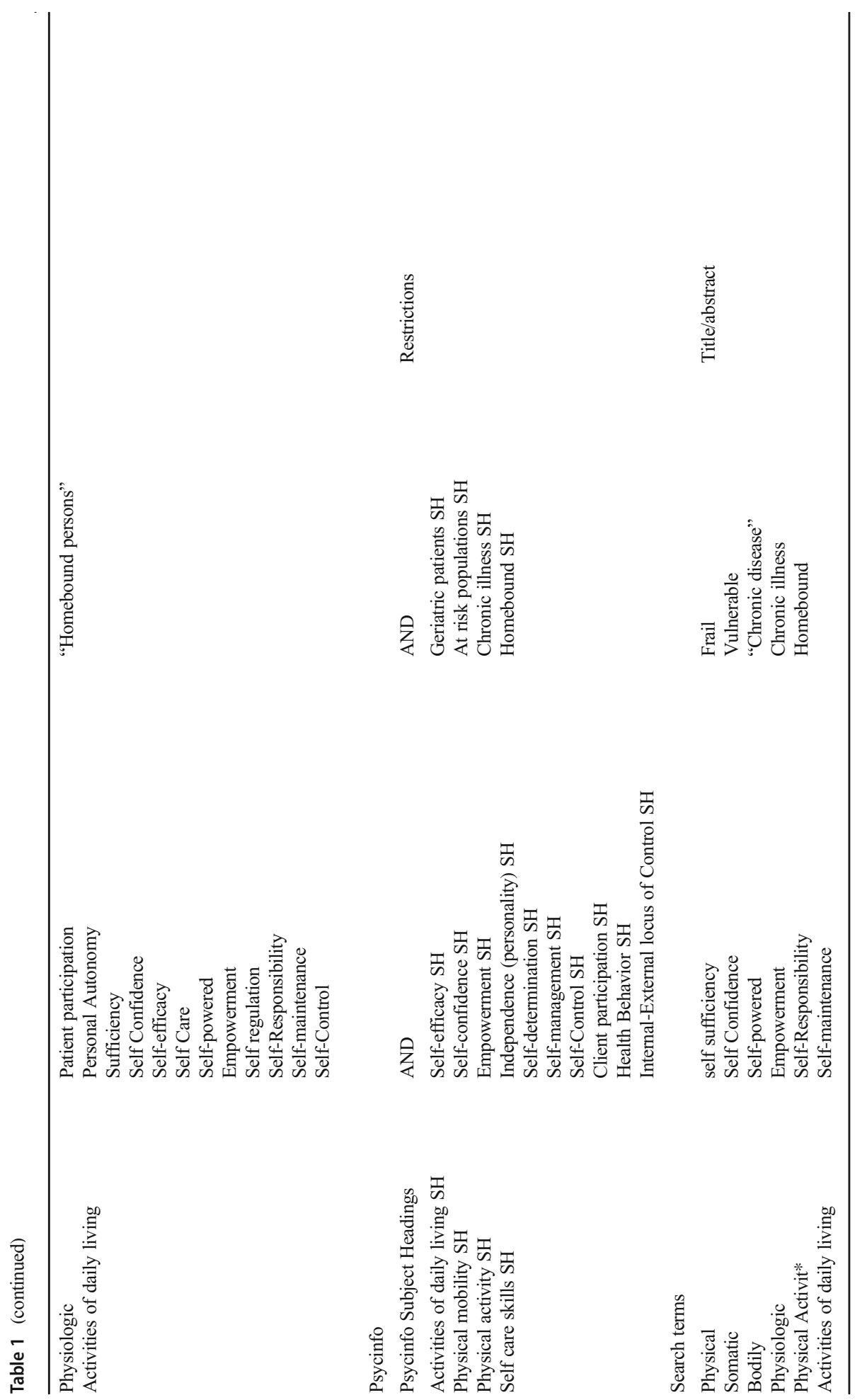




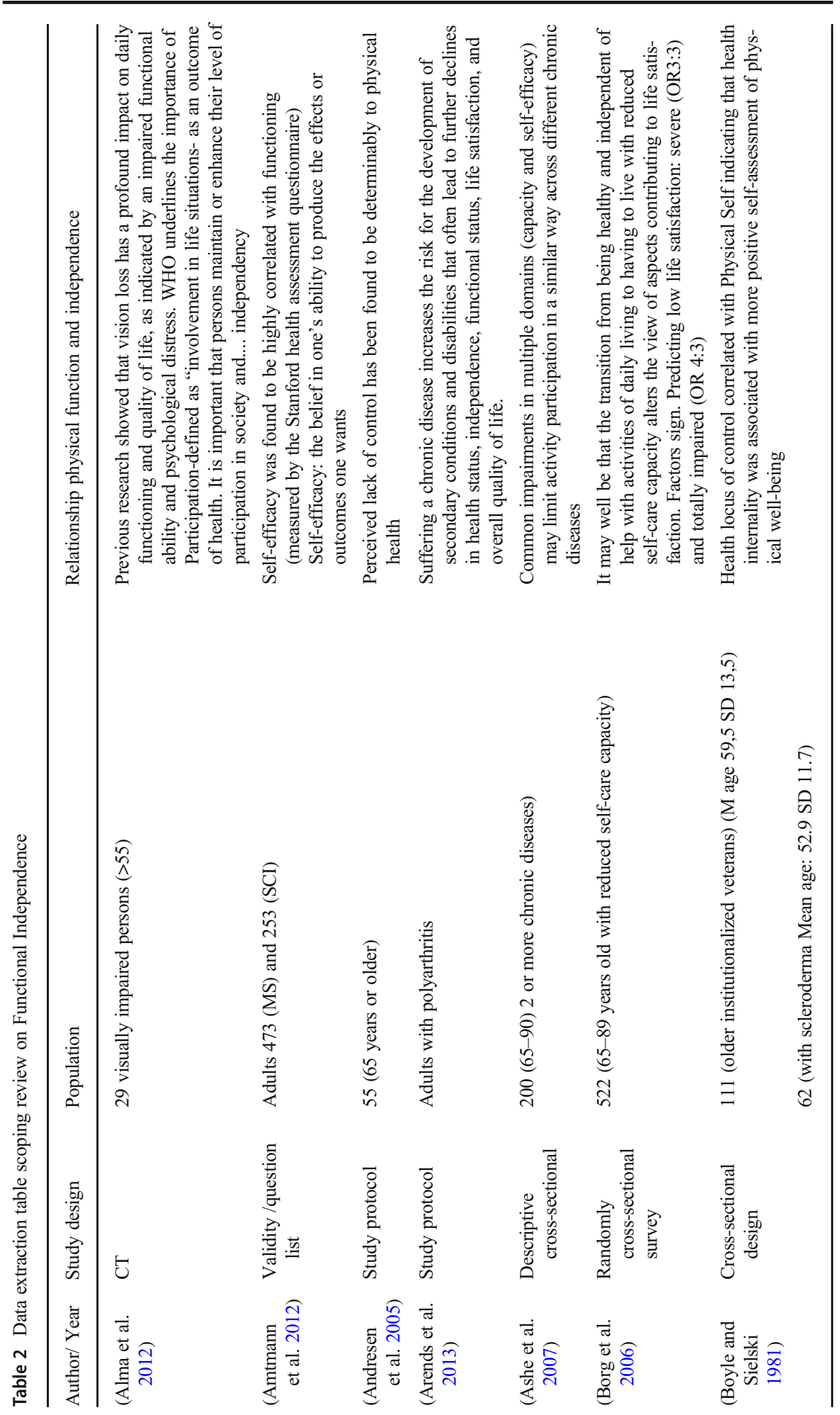




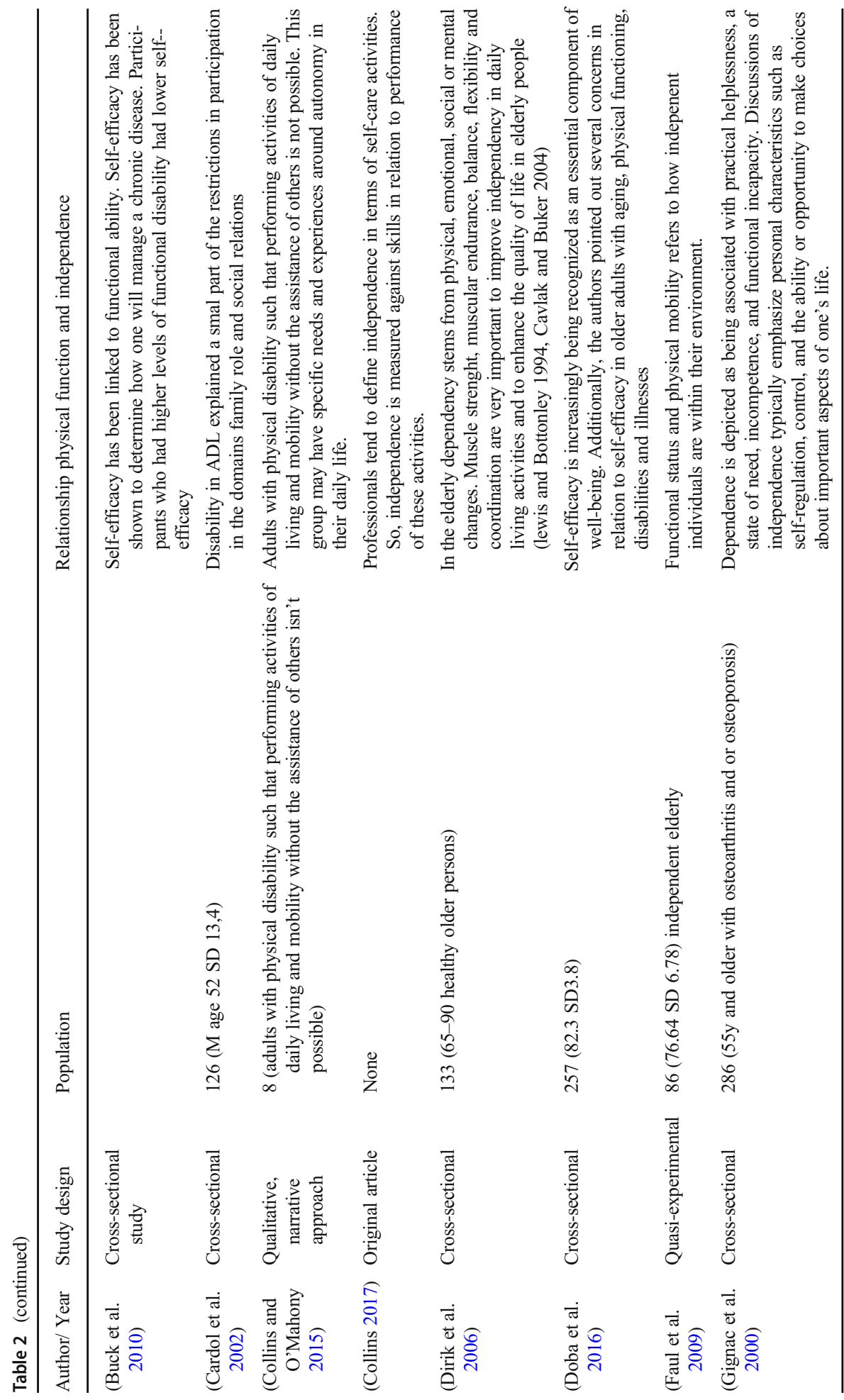




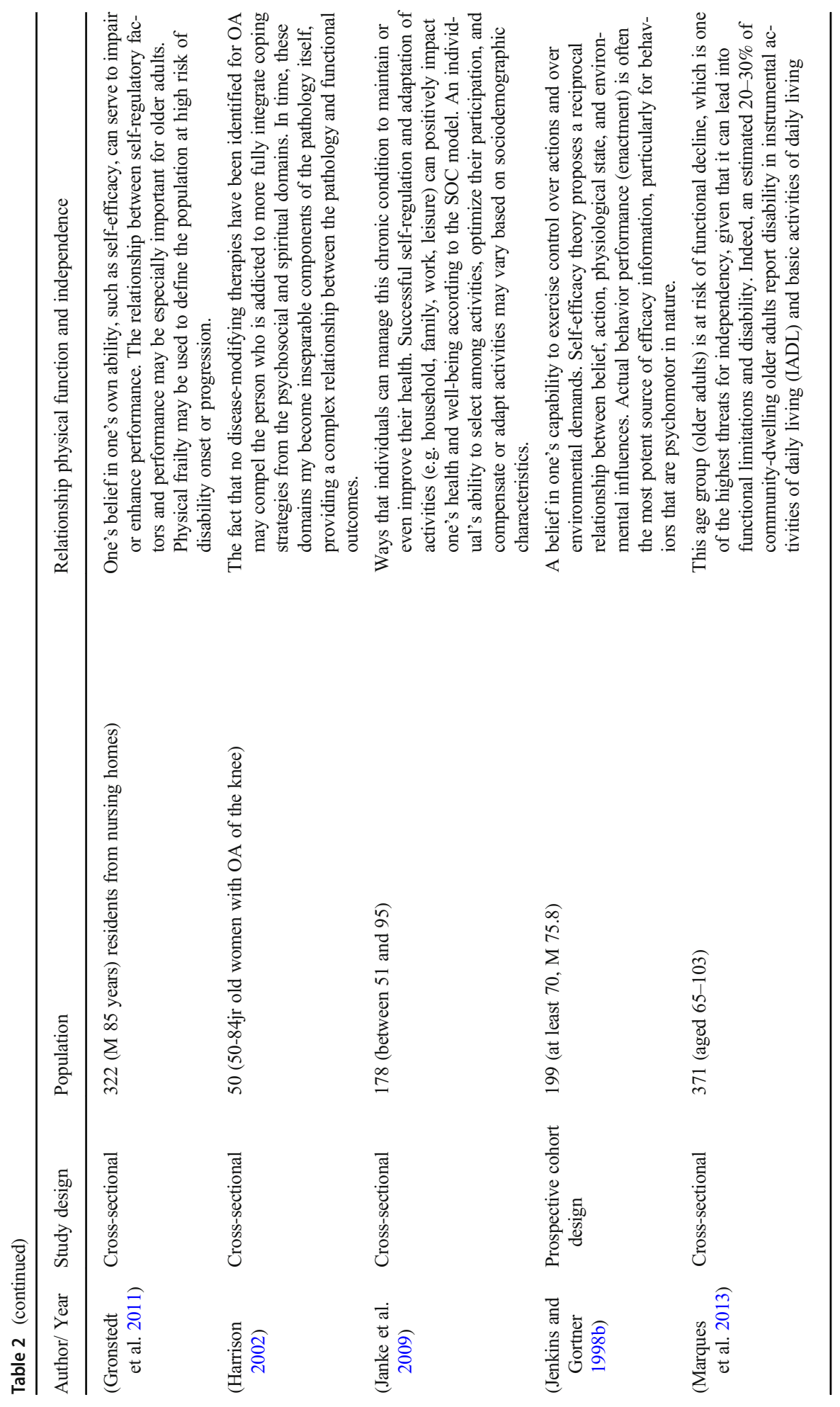




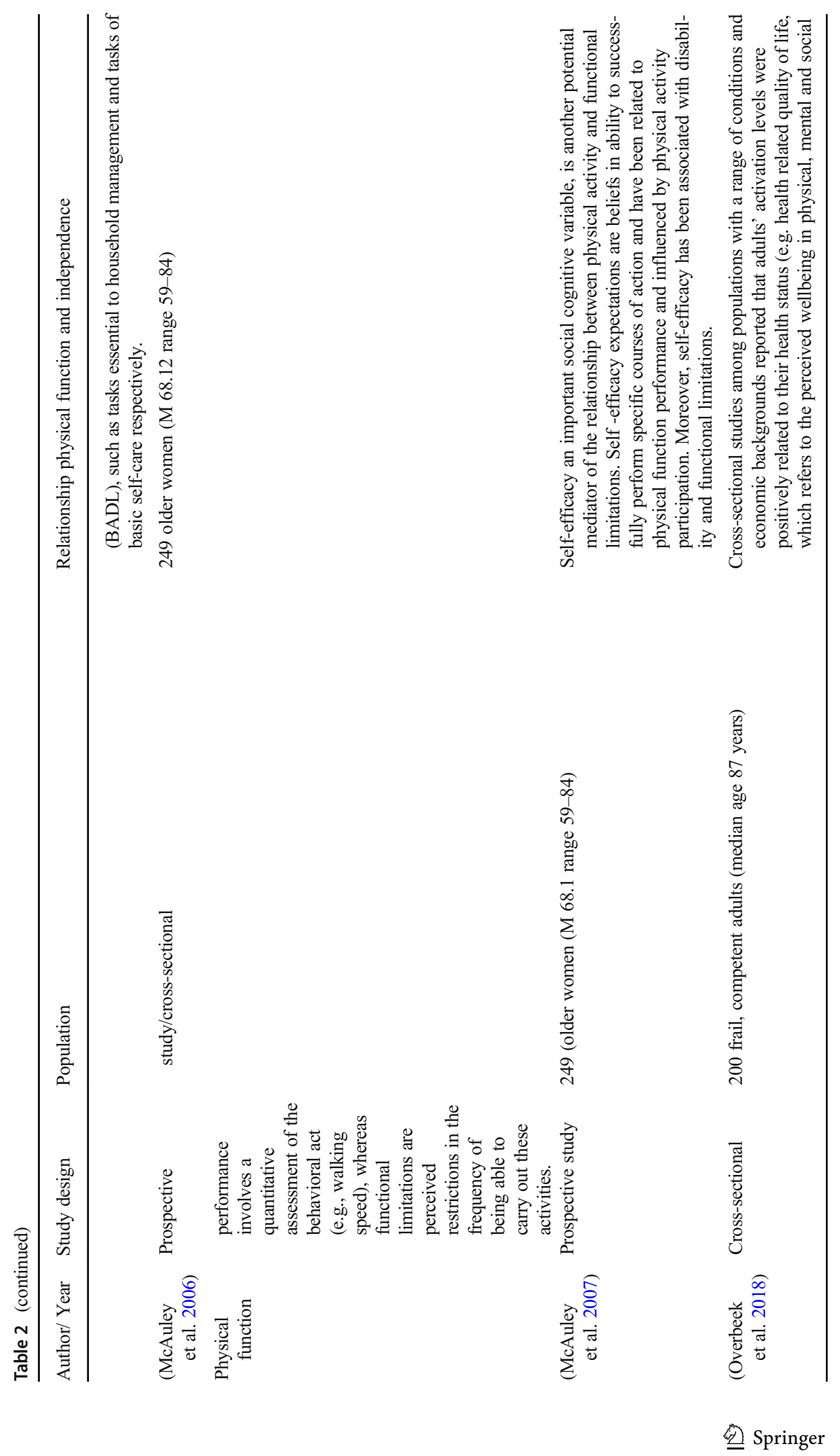




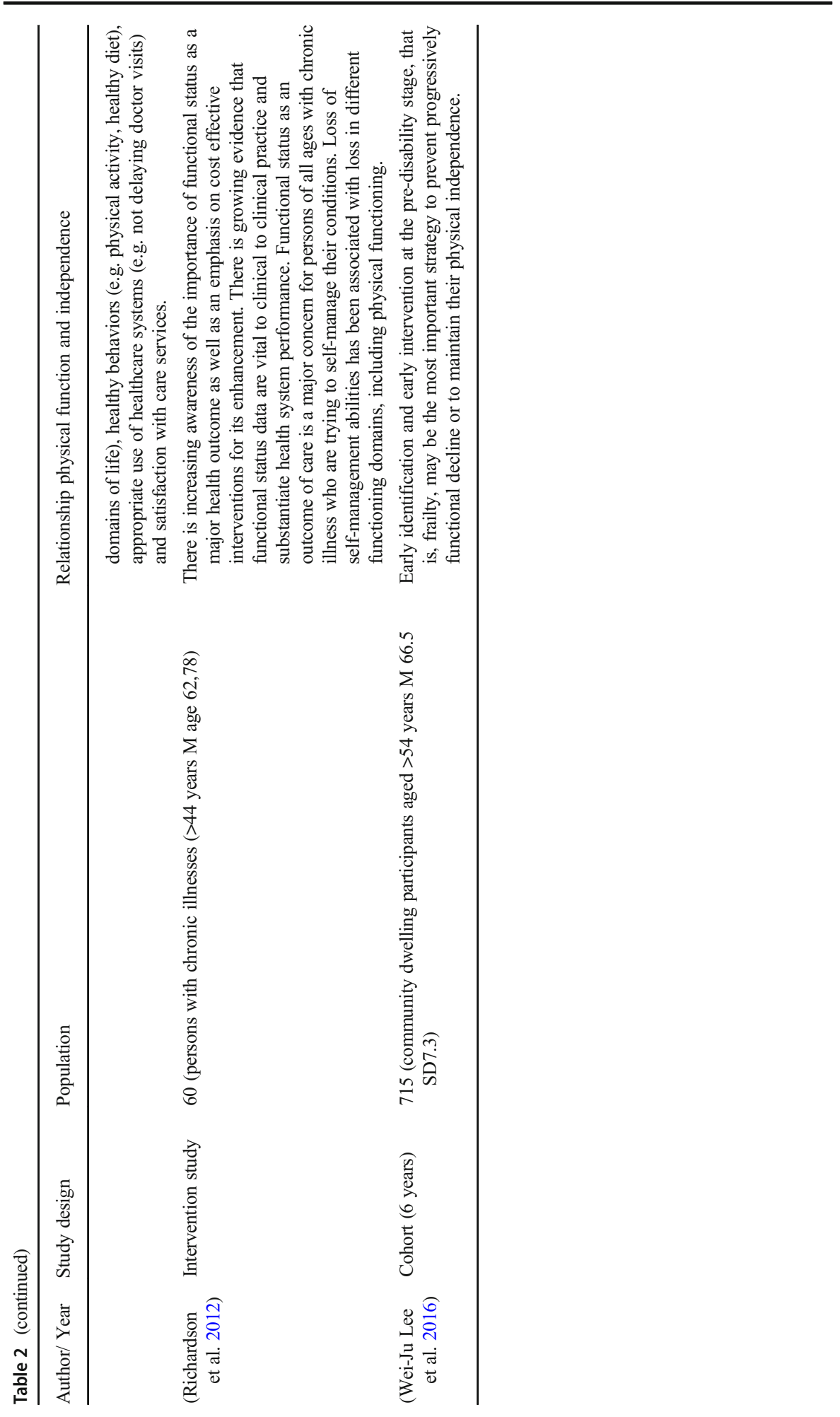


description or definition of FI (Table 2). Subsequently, the first author identified text fragments concerning FI by extensively reading the text, extracting the fragments from the included articles and identifying terms concerning FI by open coding and axial coding the text fragments according to the grounded theory (Corbin and Strauss 1990). The gathered codes were plotted in a wordcloud (Fig. 2) to identify the most commonly mentioned codes. Subsequently, these codes were used to form a preliminary, literature-based definition of FI. Furthermore, a list of key-terms related to FI was gathered, mentioned in the medical literature, to detect potential factors contributing to FI.

\section{5) Adding a clinical view and analyzing the data}

To enhance the preliminary definition and to ensure its applicability in clinical practice, relevant stakeholders in the community were consulted. Prior to consultation of stakeholders, the results of the literature review were structured by researchers and lecturers who are involved in the domain of functional independence $(n=7)$. Initially, this group was asked to reach consensus on the definition of FI in a guided focus-group discussion facilitated by the first author. Second, to gain insights into related factors of FI, the list of key-terms found in the literature was presented to the group. To involve the participants in developing an overview of related factors we used two different Participatory Learning Action techniques. With the direct ranking technique we asked participants which terms they thought contributed mostly to the definition of FI (de Brún et al. 2017). Participants were allowed to skip terms from and add terms to the list. To categorize these key terms, we used the card sort method, to democratically let the participants divide the key-terms into different main themes (Mukherjee 2002). This eventually led to a first overview of related factors influencing FI.

Subsequently, a stakeholder consultation was organized to assure the clinical relevance of the FI concept for clinical daily practice. This online consultation took place in the autumn of 2019 and involved community dwelling older persons $(N=4)$ and varying healthcare providers in community care such as occupational therapists $(n=$ $2)$, physical therapists $(n=2)$, (district) nurses $(n=4)$, physician $(n=1)$. Participants were recruited by inviting professionals who are linked to two local networks of community-care professionals through a personal e-mail. In addition, social media was used to recruit community-care professionals as well. Professionals were eligible to participate when they were involved in treatment of older people in the community. Participating professionals were requested to recruit community-dwelling older people from their professional practice. After agreement on participation participants received a personal link to provide access to the online environment which required a password. Participants were asked what their personal association was with each contributing factor to the concept of FI. Answers were discussed in the group until consensus was reached. Finally, they were asked if the factors influencing FI were adequate and if they found factors missing. Data-analyses were performed by using Atlas.ti. (version 8). First open source labeling (Corbin and Strauss 1990) was done by the first author. Second, the first two authors separately categorized these labels, outcomes were compared and discussed. Finally, the categories were added to the already obtained results and a graphic representation of FI was formed by these authors. The graphical representation adhered to the ICF framework where possible. 


\section{Results}

\section{Study Selection}

The search strategy initially resulted in a total of 1905 unique articles. After the screening process, 25 studies were eligible for inclusion. The most common exclusion criterion was a single focus on independence in general or physical output, instead of describing a physical component in relation to independence (Fig. 1).

\section{Charting the Data}

Ten studies were published over the last decade, 11 between 2000 and 2010 and only one of the studies was performed during the 90's. Most studies $(N=12)$ were cross-sectional, almost half of the included studies $(n=11)$ focused on older adults ( $>65$ years). The most commonly used words for describing the combination of the physical component and independence in the literature were 'independency', 'ability', 'functional' and 'participation'
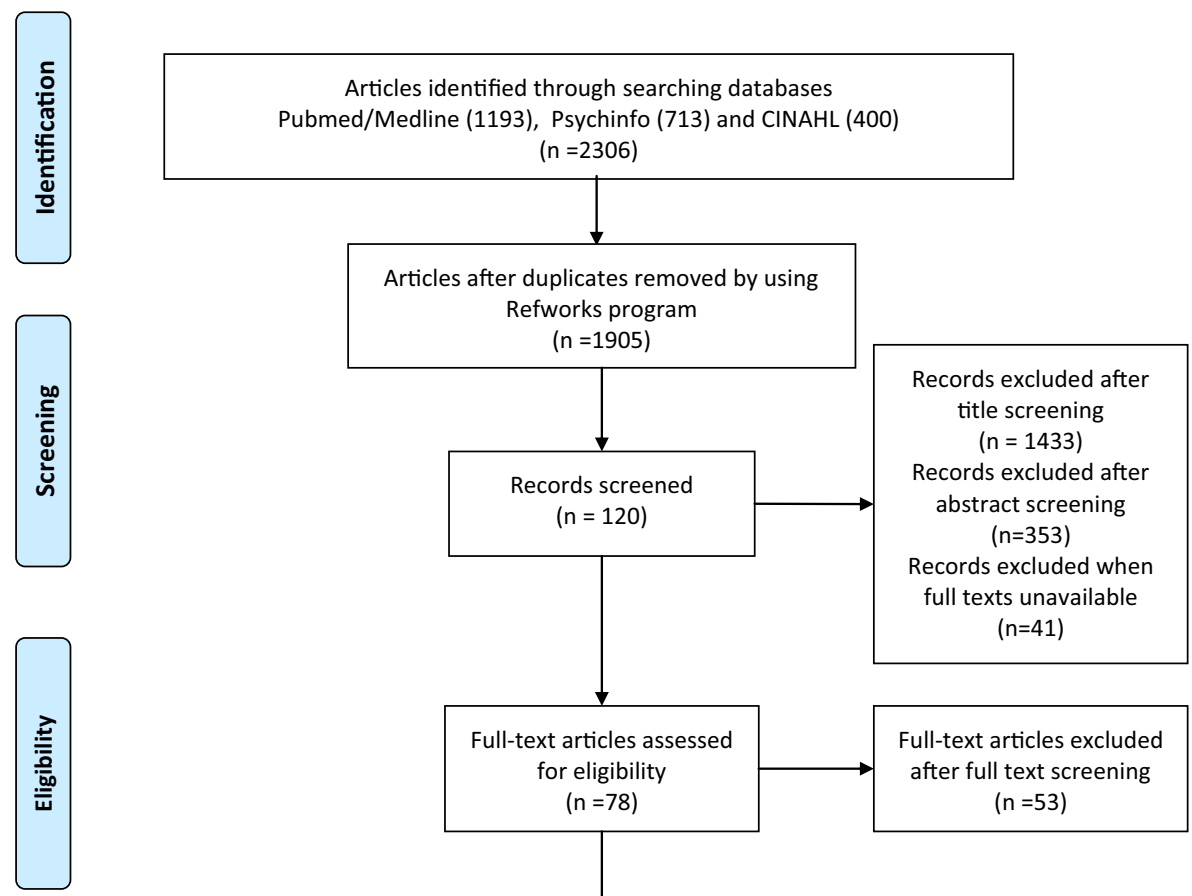
$(n=53)$
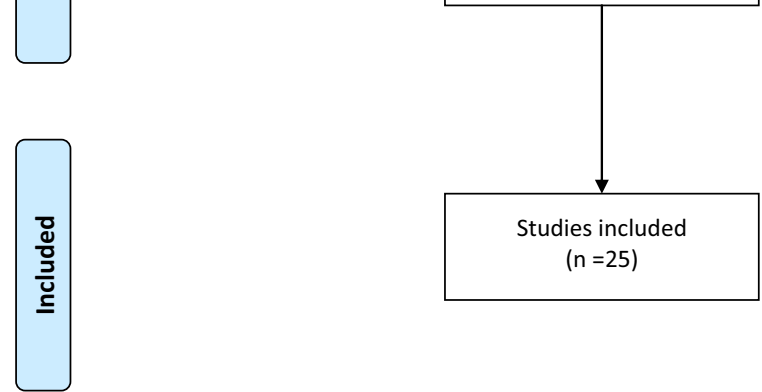

Fig. 1 Flow Diagram scoping review on Functional Independence 2019 
(Fig. 2). Further categorization by the first author, led to a preliminary definition of FI as "functioning physically independent in activities of daily life". Furthermore, the list of keyterms (available on request) mentioned in relation to the definition of FI gathered from the literature, showed terms concerning different domains as physical capacity, social participation, psychological functioning and personal environment. By way of illustration: "Mobility" (Faul et al. 2009), "Self-management" (Lee et al. 2016), "Psychological state (Jenkins and Gortner 1998a)" and "Circumstances" (Cardol et al. 2002).

\section{Adding a Clinical View and Analyzing the Data}

\section{Definition of $\mathrm{FI}$}

In addition to the preliminary definition of FI based on literature review, stakeholders mentioned the importance to include a safety-component with respect to FI based on their clinical expertise. Furthermore, participants asked for a further specification of 'independent'; it raised questions on the classification of independence when a medical instrument was used. Also the term 'daily functioning' was considered to be liable to personal interpretation. Participants finally agreed on the following definition of FI: "Functioning physically safe and independent from other persons, within one's own context”.

\section{The Comprehensive Overview of FI}

Elaborating on the definition of FI, stakeholders categorized and prioritized the key terms from the literature that were associated with FI. As a result, three domains considered to be of equal importance to FI: "physical capacity", "coping" and "context". Next to these domains, stakeholders suggested adding "empowerment" and "health literacy" as additional factors contributing to FI. Furthermore, stakeholders

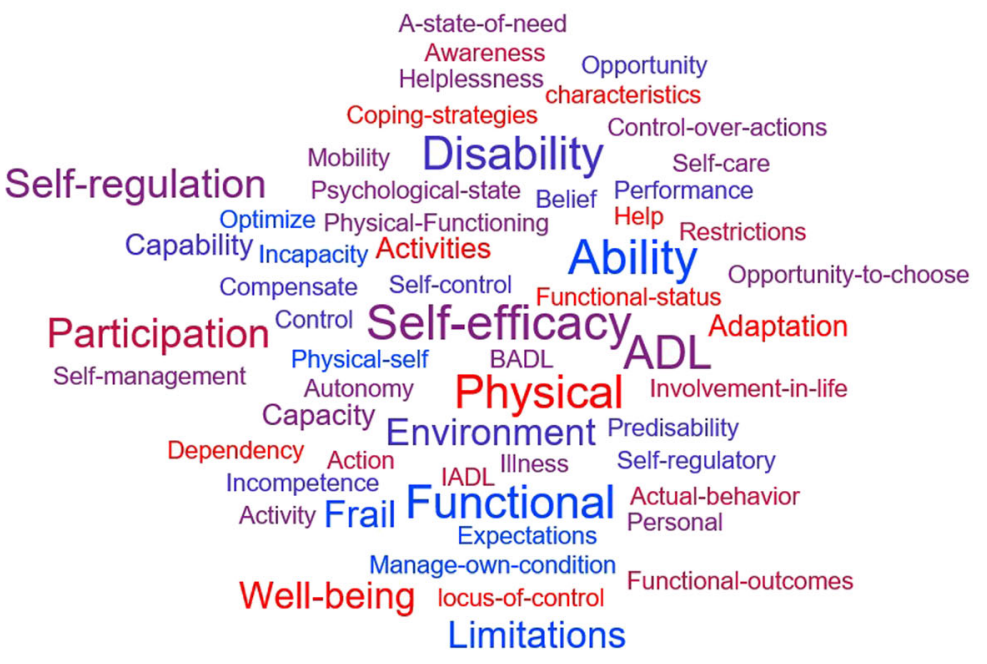

Fig. 2 Wordcloud search results from the scoping review on Functional Independence 
recommended to operationalize the factor "context" into home environment, social environment and neighborhood. With respect to the sustainability of FI, participants emphasized that FI seems to be a dynamic condition as persons can suddenly become dependent from another person due to for instance a traumatic event but then again regain their independent functioning by recovery or rehabilitation. Finally, FI should be seen as a disease-independent construct, which focusses on the ability of persons to stay independent, apart from disorders or diseases demanding salutogenesis (Mittelmark \& Bull). The comprehensive overview of FI is graphically presented in Fig. 3.

\section{Discussion}

This scoping review aimed to determine a clinical relevant definition of FI and an overview of influencing factors of FI in community-dwelling older people. As a result from the literature review and stakeholder consultation, FI could be interpreted as an interplay of physical capacity and behavioral and cognitive factors such as coping, empowerment and health literacy, that enables an older person to function physically safe and independent from other persons, within one's own context. Therewith, FI could not be seen as a discriminant outcome (functional independent versus functional dependent) but rather as a sliding scale. Someone's level of FI depends on someone's level of physical capacity influenced by personal and environmental factors. One important part of the definition of FI is 'safety'. As prior studies in older adults reported

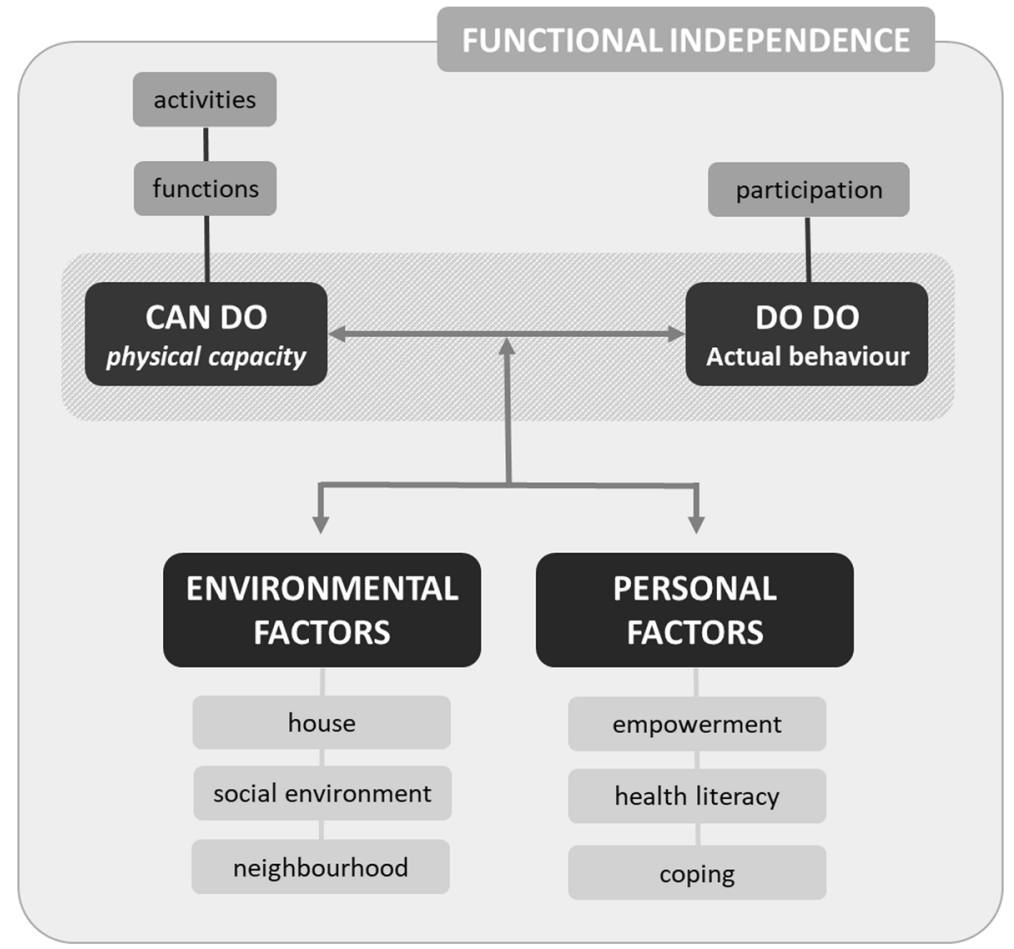

Fig. 3 The graphic presentation shows the contributing factors of Functional Independence 
that falls are a major public health issue among community dwelling older adults worldwide (Hartholt et al. 2012; Kannus et al. (1999); Marks and Allegrante 2004), this study stresses the importance of safety when considering one's FI (Collins 2017). Second, we have identified personal factors like coping, empowerment and health literacy as relevant to the concept FI. Although insufficient empowerment skills and poor health literacy are not directly associated with a loss of independent functioning they are associated with poorer health outcomes (Berkman et al. 2011; Wolf et al. 2005). In addition coping, empowerment and health literacy interact: poor health literacy causes a lack of empowerment (Edwards et al. 2012).

Results from this study are in agreement with the holistic view on a persons' health related disability's (Huber et al. 2011; Jette 2006). It enriches previous views on FI, which focused exclusively on the physical component of FI (Lamb and Keene 2017). Although we mentioned physical capacity as one of the most important contributing factors to FI, aligned with other multi-component concepts focusing on independency as the ICF (Ustun et al. 2003) and Integrated Care for Older PEople (ICOPE) guidelines (Briggs and Araujo de Carvalho 2018), the graphical presentation shows FI itself should be seen as physical performance being influenced by contextual factors, both personal and environmental factors. Furthermore the identified domains associated with FI are comparable to, for example, the physical literacy statement which also mentions the influence of cognitive and behavioral factors as knowledge and motivation besides physical competence as influencers of maintaining an active lifestyle (Tremblay et al. 2018).

\section{Strengths and Limitations}

One of the strengths of the current study was the design of the study. The scoping review design combined a literature search with a clinical view of relevant stakeholders, which is particularly suitable to explore a quite new concept like FI. Moreover, development in cocreation with the end users increases the chance of implementation in daily practice (Arksey and O'Malley 2005). The fact that FI was an unrecognized term gave the study a broad explorative character, with a broad search strategy and lacking exclusion criteria. Though, a number of limitations should be mentioned. First, as we did not filter on type of research paper, a significant amount of 'grey' literature was considered for inclusion. Unfortunately, a part of the identified articles were unavailable as full-text articles and consequently should have been excluded. Due to practical restrictions the stakeholder consultation had to be held online instead of in person, this limits the expression of emotions and can emerge misunderstanding. However, this was convenient, participants could provide input at the time which suited best, it made interaction between participants possible while not all persons had to be in a discussion simultaneously. Previous research on independency of community dwelling older people confirms the influence of contextual factors, mentioning spouses as caregivers and environmental obstacles in the home environment and neighborhood (Baker 2005; Stoller and Earl 1983).

\section{Recommendations}

This scoping review delivers a clinical and scientifically relevant definition of FI and an overview of factors contributing to FI in older people. This has several implications for 
clinical practice, health policy, health education and further research. The most important recommendation concerns interprofessionalism as the construct exceeds the border of a single profession and single ICF domain. Maintaining FI asks for a sufficient level of physical capacity, adequate coping, sufficient health literacy and empowerment, adapted to an older adult's context, and, therefore, professionals are recommended to look for interprofessional collaboration when supporting community-dwelling older people. This recommendation suits to current health policy which focuses on providing patient-centered care from a holistic perspective (Cieza et al. 2004; Gobbens and van Assen 2017; Liu 2017; Tomey and Sowers 2009). As at this moment interprofessional collaboration in the community care is still in its infancy, there is a call for financial investment, theoretical development and practical facilitation of this concept.. One of the ways to facilitate interprofessionalism both in an educational setting and clinical setting is developing a generic measurement tool to determine and monitor the level of FI in community dwelling older people.

\section{Conclusion}

This scoping review resulted in an interprofessionally supported definition of FI as "Functioning physically safely and independent from another person, within one's own context". For maintaining functional independent, sufficient physical capacities are needed but also personal and environmental factors like an adequate coping style, empowerment skills and a sufficient level of health literacy. Future research is recommended on operationalizing those factors in measurable quantities to facilitate professionals in community care to determine and monitor older people's FI in a joint manner.

Acknowledgments We would like to thank the participants of the stakeholder consultation for their time and commitment to the project.

Author Contributions Each of the co-authors has read the final version and contributed substantially to the study to qualify for co-authorship, per the guidelines of the Uniform Requirements for Manuscripts Submitted to Biomedical Journals. Furthermore the idea for the article came from E.A.L.M. Molenaar, J.A. Barten and C. Veenhof. The literature search was done by E.A.L.M. Molenaar, J.A. Barten and L. van Schoot. Data analyses and draft of the article was done by E.A.L.M. Molenaar and J.A. Barten. The other authors critically revised the work.

\section{Compliance with Ethical Standards}

Competing Interests The authors declare that they have no competing interests.

Open Access This article is licensed under a Creative Commons Attribution 4.0 International License, which permits use, sharing, adaptation, distribution and reproduction in any medium or format, as long as you give appropriate credit to the original author(s) and the source, provide a link to the Creative Commons licence, and indicate if changes were made. The images or other third party material in this article are included in the article's Creative Commons licence, unless indicated otherwise in a credit line to the material. If material is not included in the article's Creative Commons licence and your intended use is not permitted by statutory regulation or exceeds the permitted use, you will need to obtain permission directly from the copyright holder. To view a copy of this licence, visit http://creativecommons.org/licenses/by/4.0/. 


\section{References}

Alma, M. A., Groothoff, J. W., Melis-Dankers, B. J., Post, M. W., Suurmeijer, T. P., \& van der Mei, S. F. (2012). Effects of a multidisciplinary group rehabilitation programme on participation of the visually impaired elderly: A pilot study. Disability and Rehabilitation, 34(20), 1677-1685. https://doi.org/10. 3109/09638288.2012.656795.

Amtmann, D., Bamer, A. M., Cook, K. F., Askew, R. L., Noonan, V. K., \& Brockway, J. A. (2012). University of Washington self-efficacy scale: A new self-efficacy scale for people with disabilities. Archives of Physical Medicine \& Rehabilitation, 93(10), 1757-1765. https://doi.org/10.1016/j.apmr.2012.05.001.

Andresen, E. M., Malmstrom, T. K., Miller, D. K., Miller, J. P., \& Wolinsky, F. D. (2005). Retest reliability of self-reported function, self-care, and disease history. Medical Care, 43(1), 93-97 Retrieved from http:// search.ebscohost.com/login.aspx?direct=true \&db=rzh\&AN=119422365\&site=ehost-live \&scope=site.

Angus, J., Kontos, P., Dyck, I., McKeever, P., \& Poland, B. (2005). The personal significance of home: Habitus and the experience of receiving long-term home care. Sociology of Health \& Illness, 27(2), 161-187 SHIL438 [pii].

Ardali, G., Brody, L. T., States, R. A., \& Godwin, E. M. (2017). Reliability and validity of the floor transfer test as a measure of readiness for independent living among older adults. Journal of Geriatric Physical Therapy (2001). https://doi.org/10.1519/JPT.0000000000000142.

Arends, R. Y., Bode, C., Taal, E., \& Van de Laar, M. A. (2013). A goal management intervention for polyarthritis patients: Rationale and design of a randomized controlled trial. BMC Musculoskeletal Disorders, 14, 239. https://doi.org/10.1186/1471-2474-14-239.

Arksey, H., \& O’Malley, L. (2005). Scoping studies: Towards a methodological framework. International Journal of Social Research Methodology, 8(1), 19-32. https://doi.org/10.1080/1364557032000119616.

Ashe, M. C., Eng, J. J., Miller, W. C., \& Soon, J. A. (2007). Disparity between physical capacity and participation in seniors with chronic disease. Medicine \& Science in Sports \& Exercise, 39(7), 1139-1146 Retrieved from http://search.ebscohost.com/login.aspx?direct=true \&db=rzh\&AN=105996691\&site=ehost-live\&scope=site.

Baker, M. W. (2005). Creation of a model of independence for community-dwelling elders in the United States. Nursing Research, 54(5), 288-295.

Berkman, N. D., Sheridan, S. L., Donahue, K. E., Halpern, D. J., \& Crotty, K. (2011). Low health literacy and health outcomes: An updated systematic review. Annals of Internal Medicine, 155(2), 97-107. https://doi. org/10.7326/0003-4819-155-2-201107190-00005.

Bodenheimer, T. (2005). High and rising health care costs. Part 3: The role of health care providers. Annals of Internal Medicine, 142(12 Pt 1), 996-1002.

Borg, C., Hallberg, I. R., \& Blomqvist, K. (2006). Life satisfaction among older people (65+) with reduced self-care capacity: The relationship to social, health and financial aspects. Journal of Clinical Nursing, 15(5), 607-618. https://doi.org/10.1111/j.1365-2702.2006.01375.x.

Boyle, E. S., \& Sielski, K. A. (1981). Correlates of health locus of control in an older, disabled group. The Journal of Psychology, 109(1st Half), 87-91. https://doi.org/10.1080/00223980.1981.9915290.

Briggs, A. M., \& Araujo de Carvalho, I. (2018). Actions required to implement integrated care for older people in the community using the world health organization's ICOPE approach: A global delphi consensus study. PloS One, 13(10), e0205533. https://doi.org/10.1371/journal.pone.0205533.

Buck, U., Poole, J., \& Mendelson, C. (2010). Factors related to self-efficacy in persons with scleroderma. Musculoskeletal Care, 8(4), 197-203. https://doi.org/10.1002/msc.181.

Cardol, M., de Jong, B. A., van den Bos, G. A., Beelem, A., de Groot, I. J., \& de Haan, R. J. (2002). Beyond disability: Perceived participation in people with a chronic disabling condition. Clinical Rehabilitation, 16(1), 27-35. https://doi.org/10.1191/0269215502cr464oa.

Cieza, A., Ewert, T. F., FAU, U. T., Chatterji, S. F., Kostanjsek, N. F., \& Stucki, G. (2004). Development of ICF core sets for patients with chronic conditions. Journal of Rehabilitation Medicine 44, 9-11.

Clark, B. C., \& Manini, T. M. (2010). Functional consequences of sarcopenia and dynapenia in the elderly. Current Opinion in Clinical Nutrition and Metabolic Care, 13(3), 271-276. https://doi.org/10.1097/ MCO.0b013e328337819e.

Collins, B. (2017). Independence: Proposing an initial framework for occupational therapy. Scandinavian Journal of Occupational Therapy, 24(6), 398-409. https://doi.org/10.1080/11038128.2016.1271011.

Collins, B., \& O’Mahony, P. (2015). Physically disabled adults' perceptions of personal autonomy: Impact on occupational engagement. OTJR : Occupation, Participation and Health, 35(3), 160-168. https://doi.org/ $10.1177 / 1539449215575264$.

Colquhoun, H. L., Levac, D., O'Brien, K. K., Straus, S., Tricco, A. C., Perrier, L., et al. (2014). Scoping reviews: Time for clarity in definition, methods, and reporting. Journal of Clinical Epidemiology, 67(12), 1291-1294. https://doi.org/10.1016/j.jclinepi.2014.03.013. 
Corbin, J. M., \& Strauss, A. (1990). Grounded theory research: Procedures, canons, and evaluative criteria. Qualitative Sociology, 13(1), 3-21. https://doi.org/10.1007/BF00988593.

Coulter, A. (1995). Shifting the balance from secondary to primary care. BMJ, 311, 1447. https://doi.org/10. 1136/bmj.311.7018.1447.

Curzel, J., Forgiarini Junior, L. A., \& Rieder Mde, M. (2013). Evaluation of functional independence after discharge from the intensive care unit. Revista Brasileira De Terapia Intensiva, 25(2), 93-98. https://doi. org/10.5935/0103-507X.20130019.

de Brún, T., O’Reilly-de Brún, M., Van Weel-Baumgarten, E., Burns, N., Dowrick, C., Lionis, C., . . . MacFarlane, A. (2017). Using participatory learning \& action (PLA) research techniques for interstakeholder dialogue in primary healthcare: An analysis of stakeholders' experiences. Research Involvement and Engagement, 3(1), 28. https://doi.org/10.1186/s40900-017-0077-8.

de Carvalho, I. A., Epping-Jordan, J., \& Beard, J. R. (2018). Integrated care for older people; guidelines on community-level interventions to manage declines in intrinsic capacity. Geneva: World Health Organization.

Dirik, A., Cavlak, U., \& Akdag, B. (2006). Identifying the relationship among mental status, functional independence and mobility level in turkish institutionalized elderly: Gender differences. Archives of Gerontology and Geriatrics, 42(3), 339-350. Retrieved from http://131.211.208.19/login?auth= eng\&url=http://ovidsp.ovid.com/ovidweb.cgi?T=JS\&CSC=Y\&NEWS=N\&PAGE=fulltext\&D= psyc5\&AN=2006-03951-007; http://sfx.library.uu.nl/utrecht?sid=OVID:psycdb\&id=pmid: \&id=10. $1016 \% 2$ Fj.archger $.2005 .08 .007 \&$ issn $=0167-4943 \&$ isbn $=\&$ volume $=42 \&$ issue $=3 \&$ spage $=339 \&$ pages $=$ 339-350\&date $=2006 \&$ title $=$ Archives + of + Gerontology + and + Geriatrics $\&$ atitle $=$ Identifying + the + relationship+among+mental+status $\% 2 \mathrm{C}+$ functional+independence+and+mobility+level+in+Turkish+ institutionalized+elderly $\% 3 \mathrm{~A}+\mathrm{Gender}+$ differences.\&aulast=Dirik\&pid=\%3Cauthor\%3EDirik\%2C+ Ahmet\%3BCavlak\%2C+Ugur\%3BAkdag\%2C+Beyza\%3C\%2Fauthor\%3E\%3CAN\%3E2006-03951$007 \% 3 \mathrm{C} \% 2 \mathrm{FAN} \% 3 \mathrm{E} \% 3 \mathrm{CDT} \% 3 \mathrm{EJ}$ ournal+Article\%3C\%2FDT\%3E.

Doba, N., Tokuda, Y., Saiki, K., Kushiro, T., Hirano, M., Matsubara, Y., \& Hinohara, S. (2016). Assessment of self-efficacy and its relationship with frailty in the elderly. Internal Medicine (Tokyo, Japan), 55(19), 2785-2792. https://doi.org/10.2169/internalmedicine.55.6924.

Edwards, M., Wood, F., Davies, M., \& Edwards, A. (2012). The development of health literacy in patients with a long-term health condition: The health literacy pathway model. BMC Public Health, 12, 130. https://doi.org/10.1186/1471-2458-12-130.

Edwards, L. C., Bryant, A. S., Keegan, R. J., Morgan, K., \& Jones, A. M. (2017). Definitions, foundations and associations of physical literacy: A systematic review. Sports Medicine (Auckland, N.Z.), 47(1), 113-126. https://doi.org/10.1007/s40279-016-0560-7.

Faul, A. C., Yankeelov, P. A., Rowan, N. L., Gillette, P., Nicholas, L. D., Borders, K. W., et al. (2009). Impact of geriatric assessment and self-management support on community-dwelling older adults with chronic illnesses. Journal of Gerontological Social Work, 52(3), 230-249. https://doi.org/10.1080/ 01634370802609288.

Freedman, V. A., Martin, L. G., \& Schoeni, R. F. (2002). Recent trends in disability and functioning among older adults in the United States: A systematic review. Jama, 288(24), 3137-3146.

Gignac, M. A. M., Cott, C., \& Badley, E. M. (2000). Adaptation to chronic illness and disability and its relationship to perceptions of independence and dependence. The Journals of Gerontology: Series B: Psychological Sciences and Social Sciences, 55(6), P362-P372. Retrieved from http://131.211.208.19/login?auth=eng\&url=http:// ovidsp.ovid.com/ovidweb.cgi?T=JS\&CSC=Y\&NEWS=N\&PAGE=fulltext\&D=psyc3\&AN=2000-12385005; http://sfx.library.uu.nl/utrecht?sid=OVID:psycdb\&id=pmid:\&id=10.1093\%2Fgeronb\%2F55.6. $\mathrm{P} 362 \&$ issn $=1079-5014 \&$ isbn $=\&$ volume $=55$ \&issue $=6$ \&spage $=\mathrm{P} 362$ \&pages $=\mathrm{P} 362-\mathrm{P} 372 \&$ date $=2000 \&$ title $=$ The+Journals+of+Gerontology $\% 3 \mathrm{~A}+$ Series+B $\% 3 \mathrm{~A}+$ Psychological+Sciences+and+Social+Sciences\&atitle= Adaptation+to+chronic+illness+and+disability+and+its+relationship+to+perceptions+of+independence+and+ dependence.$\&$ aulast $=$ Gignac $\&$ pid $=\% 3$ Cauthor $\% 3$ EGignac $\% 2 \mathrm{C}+$ Monique $+\mathrm{A} .+\mathrm{M} \% 3 \mathrm{BCott} \% 2 \mathrm{C}+\mathrm{Cheryl} \%$ 3BBadley\%2C+Elizabeth+M\%3C\%2Fauthor\%3E\%3CAN\%3E2000-12385-005\%3C\%2FAN\%3E\%3CDT\% 3EJournal+Article\%3C\%2FDT\%3E.

Glenny, C., \& Stolee, P. (2009). Comparing the functional independence measure and the interRAI/MDS for use in the functional assessment of older adults: A review of the literature. BMC Geriatrics, 9, 52-52. https://doi.org/10.1186/1471-2318-9-52.

Gobbens, R., \& van Assen, M. (2017). Associations between multidimensional frailty and quality of life among dutch older people. Archives of Gerontology and Geriatrics, 73, 69-76. https://doi.org/10.1016/j. archger.2017.07.007. 
Gronstedt, H., Hellstrom, K., Bergland, A., Helbostad, J. L., Puggaard, L., Andresen, M., et al. (2011). Functional level, physical activity and wellbeing in nursing home residents in three nordic countries. Aging Clinical and Experimental Research, 23(5-6), 413-420. https://doi.org/10.3275/7507.

Harrison, A. L. (2002). The influence of pathology, pain, and coping on function among older women with knee osteoarthritis (Ph.D.). Available from EBSCOhost; rzh. (109842116). Retrieved from http://search. ebscohost.com/login.aspx?direct=true \&db=rzh\&AN=109842116\&site=ehost-live\&scope=site.

Hartholt, K. A., Polinder, S., Van der Cammen, Tisha J. M., Panneman, M. J. M., Van der Velde, N., Van Lieshout, E. M. M., . . V Van Beeck, E. F. (2012). Costs of falls in an ageing population: A nationwide study from the Netherlands (2007-2009). Injury, 43(7), 1199-1203. https://doi.org/10.1016/j.injury.2012.03.033.

Huber, M., Knottnerus, J. A., Green, L., van der Horst, H., Jadad, A. R., Kromhout, D., et al. (2011). How should we define health? BMJ (Clinical Research Ed.), 343, d4163. https://doi.org/10.1136/bmj.d4163.

Janke, M. C., Son, J. S., \& Payne, L. L. (2009). Self-regulation and adaptation of leisure activities among adults with arthritis. Activities, Adaptation \& Aging, 33(2), 65-80 Retrieved from http://search.ebscohost. com/login.aspx ?direct=true $\& \mathrm{db}=\mathrm{rzh} \& \mathrm{AN}=105376198 \&$ site=ehost-live $\&$ scope $=$ site.

Jenkins, L. S., \& Gortner, S. R. (1998a). Correlates of self-efficacy expectation and prediction of walking behavior in cardiac surgery elders. Annals of Behavioral Medicine, 20(2), 99-103. Retrieved from http://131.211.208. 19/login?auth=eng\&url=http://ovidsp.ovid.com/ovidweb.cgi?T=JS\&CSC=Y\&NEWS=N\&PAGE= fulltext\&D=psyc3\&AN=1999-00988-008; http://sfx.library.uu.nl/utrecht?sid=OVID:psycdb\&id=pmid:\&id= $10.1007 \% 2 \mathrm{FBF} 02884455 \&$ issn $=0883-6612 \&$ isbn $=\&$ volume $=20 \&$ issue $=2 \&$ spage $=99 \&$ pages $=99$ $103 \&$ date $=1998 \&$ title $=$ Annals + of + Behavioral + Medicine $\&$ atitle $=$ Correlates + of + self-efficacy + expectation + and+prediction+of+walking+behavior+in+cardiac+surgery+elders. \&aulast=Jenkins\&pid=\%3Cauthor\% 3EJenkins\%2C+Louise+S\%3BGortner\%2C+Susan+R\%3C\%2Fauthor\%3E\%3CAN\%3E1999-00988$008 \% 3 \mathrm{C} \% 2 \mathrm{FAN} \% 3 \mathrm{E} \% 3 \mathrm{CDT} \% 3 \mathrm{EJ}$ ournal+Article\%3C\%2FDT\%3E.

Jenkins, L. S., \& Gortner, S. R. (1998b). Correlates of self-efficacy expectation and prediction of walking behavior in cardiac surgery elders. Annals of Behavioral Medicine, 20(2), 99-103. Retrieved from http://131.211.208. 19/login?auth=eng\&url=http://ovidsp.ovid.com/ovidweb.cgi?T=JS\&CSC=Y\&NEWS=N\&PAGE= fulltext\&D=psyc3\&AN=1999-00988-008; http://sfx.library.uu.nl/utrecht?sid=OVID:psycdb\&id=pmid:\&id= $10.1007 \% 2 \mathrm{FBF} 02884455 \&$ issn $=0883-6612 \&$ isbn $=\&$ volume $=20 \&$ issue $=2 \&$ spage $=99 \&$ pages $=99$ $103 \&$ date $=1998 \&$ title $=$ Annals + of + Behavioral + Medicine $\&$ atitle $=$ Correlates + of + self-efficacy + expectation + and+prediction+of+walking+behavior+in+cardiac+surgery+elders.\&aulast=Jenkins\&pid=\%3Cauthor\% 3EJenkins\%2C+Louise+S\%3BGortner\%2C+Susan+R\%3C\%2Fauthor\%3E\%3CAN\%3E1999-00988$008 \% 3 \mathrm{C} \% 2 \mathrm{FAN} \% 3 \mathrm{E} \% 3 \mathrm{CDT} \% 3 \mathrm{EJ}$ ournal+Article $\% 3 \mathrm{C} \% 2 \mathrm{FDT} \% 3 \mathrm{E}$.

Jette, A. M. (2006). Toward a common language for function, disability, and health. Physical Therapy, 86(5), 726-734. https://doi.org/10.1093/ptj/86.5.726.

Kannus, P., Parkkari, J., Koskinen, S., Niemi, S., Palvanen, M., Järvinen, M., \& Vuori, I. (1999). Fall-induced injuries and deaths among older adults. JAMA, 281(20), 1895-1899. https://doi.org/10.1001/jama.281.20.1895.

Lamb, S. E., \& Keene, D. J. (2017). Measuring physical capacity and performance in older people. Best Practice \& Research Clinical Rheumatology, 31(2), 243-254.

Lee, W.-J., Chen, L.-K., Peng, L.-N., Chiou, S.-T., Chou, P., Lee, W., . . Chou, P. (2016). Personal mastery attenuates the adverse effect of frailty on declines in physical function of older people: A 6-year population-based cohort study. Medicine, 95(34), 1-7. https://doi.org/10.1097/MD.0000000000004661.

Liu, J. Y. (2017). The severity and associated factors of participation restriction among community-dwelling frail older people: An application of the international classification of functioning, disability and health (WHO-ICF). BMC Geriatrics, 17(1), 43. https://doi.org/10.1186/s12877-017-0422-7.

Mahoney, F. I., \& Barthel, D. W. (1965). Functional evaluation: The barthel index. Maryland State Medical Journal, 14, 61-65.

Marks, R., \& Allegrante, J. P. (2004). Falls-prevention programs for older ambulatory community dwellers: From public health research to health promotion policy. Sozial- Und Praventivmedizin, 49(3), 171-178.

Marques, A., Jacome, C., Gabriel, R., \& Figueiredo, D. (2013). Comprehensive ICF core set for obstructive pulmonary diseases: Validation of the activities and participation component through the patient's perspective. Disability and Rehabilitation, 35(20), 1686-1691. https://doi.org/10.3109/09638288.2012.750691.

Mateen, F. J., Oh, J., Tergas, A. I., Bhayani, N. H., \& Kamdar, B. B. (2013). Titles versus titles and abstracts for initial screening of articles for systematic reviews. Clinical Epidemiology, 5, 89-95. https://doi.org/10. 2147/CLEP.S43118.

McAuley, E., Konopack, J. F., Morris, K. S., Motl, R. W., Hu, L., Doerksen, S. E., \& Rosengren, K. (2006). Physical activity and functional limitations in older women: Influence of self-efficacy. The Journals of Gerontology Series B, Psychological Sciences and Social Sciences, 61(5), P270-P277.

McAuley, E., Morris, K. S., Doerksen, S. E., Motl, R. W., Liang, H., White, S. M., WÃ $\tilde{3}^{3}$ cicki, T. R., \& Rosengren, K. (2007). Effects of change in physical activity on physical function limitations in older 
women: Mediating roles of physical function performance and self-efficacy. Journal of the American Geriatrics Society, 55(12), 1967-1973 JGS1469 [pii].

Mortenson, W. B., Demers, L., Fuhrer, M. J., Bilkey, J., Jutai, J., Alkadri, J., \& Aziz, J. (2018). Comparing assessments of physical functional independence in older adults with mobility limitations. American Journal of Physical Medicine \& Rehabilitation. https://doi.org/10.1097/PHM.0000000000001092.

Mukherjee, N. (2002). Participatory learning and action, with 100 field methods ((No.4) ed.). New Delhi: Concept Publishing Company.

Overbeek, A., Rietjens, J. A. C., Jabbarian, L. J., Severijnen, J., Swart, S. J., van der Heide, A., \& Korfage, I. J. (2018). Low patient activation levels in frail older adults: A cross-sectional study. BMC Geriatrics, 18(1), 7. https://doi.org/10.1186/s12877-017-0696-9.

Richardson, J., Letts, L., Chan, D., Officer, A., Wojkowski, S., Oliver, D., et al. (2012). Monitoring physical functioning as the sixth vital sign: Evaluating patient and practice engagement in chronic illness care in a primary care setting-a quasi-experimental design. BMC Family Practice, 13, 29. https://doi.org/10.1186/ 1471-2296-13-29.

Sangaleti, C., Schveitzer, M. C., Peduzzi, M., Zoboli, E. L. C. P., \& Soares, C. B. (2017). Experiences and shared meaning of teamwork and interprofessional collaboration among health care professionals in primary health care settings: A systematic review. JBI Database of Systematic Reviews and Implementation Reports, 15(11), 2723-2788. https://doi.org/10.11124/JBISRIR-2016-003016.

Stoller, E. P., \& Earl, L. L. (1983). Help with activities of everyday life: Sources of support for the noninstitutionalized elderly. The Gerontologist, 23(1), 64-70. https://doi.org/10.1093/geront/23.1.64.

Tomey, K. M., \& Sowers, M. R. (2009). Assessment of physical functioning: A conceptual model encompassing environmental factors and individual compensation strategies. Physical Therapy, 89(7), 705-714. https://doi.org/10.2522/ptj.20080213.

Tremblay, M. S., Costas-Bradstreet, C., Barnes, J. D., Bartlett, B., Dampier, D., Lalonde, C., ... Yessis, J. (2018). Canada's physical literacy consensus statement: Process and outcome. BMC Public Health, 18(Suppl 2). https://doi.org/10.1186/s12889-018-5903-X.

Ustun, T. B., Chatterji, S., Bickenbach, J., Kostanjsek, N., \& Schneider, M. (2003). The international classification of functioning, disability and health: A new tool for understanding disability and health. Disability and Rehabilitation, 25(11-12), 565-571. https://doi.org/10.1080/0963828031000137063.

Wallace, M., Shelkey, M., \& Hartford Institute for Geriatric Nursing. (2007). Katz index of independence in activities of daily living (ADL). Urologic Nursing, 27(1), 93-94.

Wolf, M. S., Gazmararian, J. A., \& Baker, D. W. (2005). Health literacy and functional health status among older adults. Archives of Internal Medicine, 165(17), 1946-1952. https://doi.org/10.1001/archinte.165.17.1946.

Publisher's Note Springer Nature remains neutral with regard to jurisdictional claims in published maps and institutional affiliations.

\section{Affiliations}

\section{E. A. L. M. Molenaar ${ }^{1,2} \cdot$ J. A. Barten ${ }^{1} \cdot$ S. te Velde $^{1} \cdot$ L. van der Schoot $^{3} \cdot$ N. Bleijenberg $^{4,5} \cdot$ N. J. de Wit ${ }^{4,5} \cdot$ C. Veenhof ${ }^{1,2,5}$}

1 Research Group Innovation of Human Movement Care, Research Centre for Healthy and Sustainable Living, Utrecht University of Applied Sciences, Utrecht, The Netherlands

2 University Medical Center Utrecht, Department of Rehabilitation, Physical Therapy Science \& Sports, Brain Center Rudolf Magnus, Utrecht University, Utrecht, Netherlands

3 Institute of Movement Studies, Utrecht University of Applied Sciences, Utrecht, The Netherlands

4 Department of General Practice, Julius Center for Health Sciences and Primary Care, University Medical Center Utrecht, Utrecht University, Utrecht, The Netherlands

5 Center for Physical Therapy Research and Innovation in Primary Care, Julius Health Care Centers, Utrecht, The Netherlands 